\title{
A Clinicopathologic Correlation Study of Thallium-201 Myocardial Scintigraphy in Diagnosis of Myocardial Infarction
}

Kouji Chida, M.D., Masaya Suglura, M.D., Shin-ichiro Ohkawa, M.D., Toshiyuki Takahashi, M.D., Jun-ichi Suzuki, M.D., Keiji Ueda, M.D., Hiromi Tabuchi, M.D., * Hajime Murata, M.D.,* Jun-ichi Nagashima, M.D., * Kazuo Chiba, M.D.,* and Hideo Yamada, M.D.*

\section{SUMmary}

In a series of 1,000 consecutive autopsy cases, we evaluated the clinical utility of thallium-201 (Tl-201) myocardial scintigraphy and electrocardiography (ECG) in 101 patients who had been studied while alive. Fifty-five cases had myocardial infarctions (MI) at autopsy. The Tl-201 scintigram and ECG in diagnosis of MI showed sensitivities of $68 \%$ and $60 \%$, specificities of $87 \%$ and $83 \%$, and diagnostic accuracies of $76 \%$ and $70 \%$, respectively. The sensitivity of the Tl-201 scintigram was $70 \%$ in anterior MI, $80 \%$ in postero-inferior $\mathrm{MI}, 25 \%$ in lateral and subendocardial infarction. The sensitivity was $88 \%$ for large massive MI, but was low in scattered $(50 \%)$ or middle-sized MI (17\%). The diagnostic limit of the resolution of Tl-201 scintigrams was $4.5 \mathrm{~cm}$ in long diameter. All 8 cases with MI of less than $4 \mathrm{~cm}$ could not be diagnosed with the technique. There were 4.8 cases of large MI (more than $5 \mathrm{~cm}$ ), but 8 cases could not be diagnosed by scintigraphy because of non-transmural or scattered MI. A comparison of the Tl-201 scintigram and ECG showed that 27 cases out of 60 cases were diagnosed by both methods, 14 only by the Tl-201 scintigram, 9 only by ECG and 10 by neither method.

\section{Additional Indexing Words:}

Autopsy Scintigraphic defect Transmural infarction

Non-transmural infarction

From the Division of Cardiology, and Division of Radiology and Nuclear Medicine,* Tokyo Metropolitan Geriatric Hospital, Tokyo.

Address for reprint: Kouji Chida, M.D., Department of Medicine, Tokyo Metropolitan Geriatric Hospital, 35-2 Sakae-cho, Itabashi-ku, Tokyo 173, Japan.

Received for publication May 26, 1986.

Manuscript revised August 25, 1986. 
LECTROCARDIOGRAPHY, serum enzymes and ultrasonic echocardiography have been used in the diagnosis of myocardial infarction (MI). Myocardial perfusion scintigraphy with thallium-201 (Tl-201) is regarded as a recent advancement for diagnosing MI. However, clinicopathologic correlation studies between $\mathrm{Tl}-201$ myocardial scintigraphy and pathologic findings are still scanty. ${ }^{1)-7}$

In our previous clinicopathologic study of T1-201 myocardial scintigraphy in 47 cases ( 26 with MI and 21 without MI), it was concluded that the size threshold for MI detection of T1-201 was $5 \mathrm{~cm}$ in long diameter." The purpose of the present study was to assess the utility and limitations of Tl-201 scintigrams and electrocardiography on the basis of pathologic findings in 101 patients.

\section{Materials and Methods}

In a series of 1,000 consecutive autopsy cascs (during 3.5 years from September, 1980 to February, 1984), 101 patients had been examined with Tl-201 scintigraphy while alive. This population consisted of 47 men and 54 women, ranging in age from 63 to 93 (average age of 79 years). Fiftyfive patients had a total of 60 previous myocardial infarctions. Myocardial images were recorded $10 \mathrm{~min}$ after an intravenous injection of $2 \mathrm{mCi}$ of ionic thallium-201 at rest, using a Searle PHO Gamma V scintillation camera with a converging collimeter. Myocardial images were obtained in four different views (anterior, left oblique $30^{\circ}$ and $60^{\circ}$, and left lateral), acquiring 400,000 counts for each view. The site of scintigraphic defects was diagnosed as anterior (including antero-septal), inferior (including infero-septal) and lateral. A lesion at the apical portion was included in either involved adjacent myocardial segment. Each scintigram was evaluated visually by 2 radiologists, without knowledge of the clinical and pathologic findings, and was divided into positive (definitely abnormal or probably abnormal) and negative (probably normal or definitely normal) categories.

Twclve-lead electrocardiograms were also reviewed. An old MI was diagnosed when pathologic $Q$ waves of $\geqq 0.04$ sec in duration and the following $\mathrm{R}$ waves of at least $25 \%$ were present, and acute MI was diagnosed when new pathologic $Q$ waves and ST-T changes developed. Subendocardial infarction was diagnosed when significant ST-T changes and a typical enzyme pattern were present. A MI in patients with left bundle branch block (LBBB) was diagnosed in the same way.

At autopsy, the heart specimens were cut into four or five transverse slices with a thickness of 0.8 to $1.5 \mathrm{~cm}$, after fixation in $10 \%$ formaldehyde. 
A MI was diagnosed by gross examination when myocardial necrosis or a scar was more than $1 \mathrm{~cm}$ long in diameter. Microscopic studies were also performed. A MI was classified as anterior (including antero-septal), posterior (including postero-septal), lateral or subendocardial infarction. MI was also classified according to the types of wall involvement: massive or scattered, and transmural or non-transmural. ${ }^{8,9)}$ The size of the MI was expressed as large ( $>5 \mathrm{~cm}$ for longest diameter), middle-sized $(2-5 \mathrm{~cm})$ and small (1$2 \mathrm{~cm}$.8) The MIs which occurred after Tl-201 scintigraphy were included in the control group. Unpaired t-tests and Chi-square tests were used to assess differences between the groups.

\section{Results}

I. Clinical course of MI

Fig. 1 shows the latencies from the onset of the MI to Tl-201 scintigraphy and latencies from Tl-201 examination to death in 55 patients with a pathologically verified MI. The intervals from the onset of MI to Tl-201 scintigraphy

Clinical Course of Myocardial Infarction (55 cases)

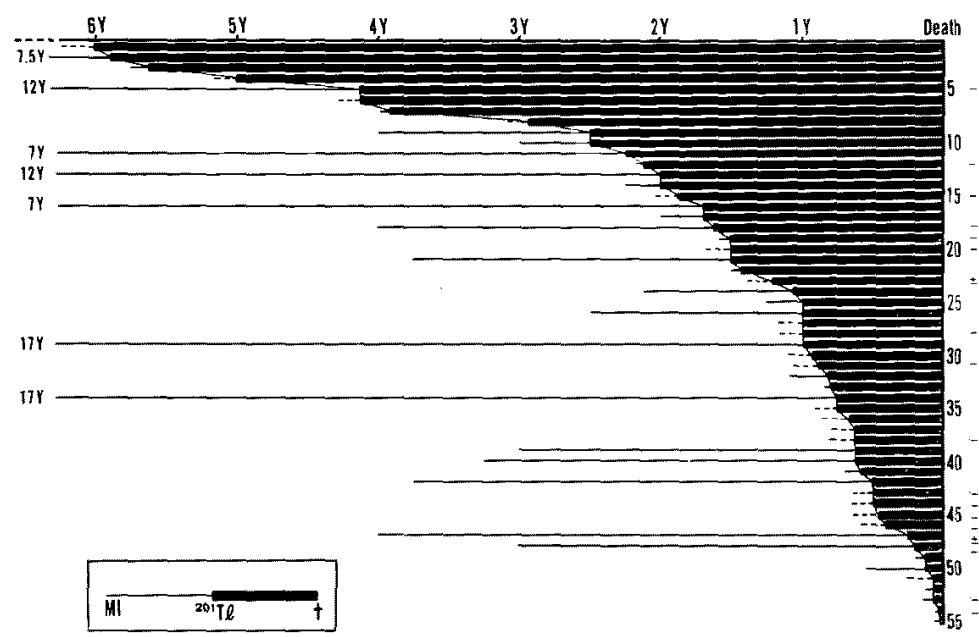

Fig. 1. Clinical course of myocardial infarction in 55 cases. The thin bar represents the interval between the onset of the MI and Tl-201 scintigraphy; the thick bar represents the interval between Tl-201 scintigraphy and death. The dotted line represents cases with an unknown MI onset. Along the vertical line, case numbers were plotted with the scintigraphic results; $\Theta$ means negative defects, and $\Theta$ positive and negative defects in cases with 2 separate MIs. Cases without marks indicate positive scintigraphic defects. 
Table I. Diagnosis of Myocardial Infarction - Autopsy and 201Tl Scintigram-

\begin{tabular}{|c|c|c|c|c|c|c|}
\hline \multicolumn{2}{|c|}{ size ${ }_{\text {nature }}$ site } & Anterior & Postero-inferior & Lateral & Subendocardial & Sensitivity \\
\hline \multirow{2}{*}{ 㱒 } & massive & $\begin{array}{l}00000 \\
0000000 \\
000^{*} 0^{*} 0^{\circ}\end{array}$ & $\begin{array}{l}000000 \\
000000 \\
0000^{* 0}\end{array}$ & 0 & $\bullet$ & $\frac{35}{40} 87.5 \%$ \\
\hline & scattered & $\circ \bullet \bullet$ & 00 & $\bullet$ & $\circ \bullet$ & $\frac{4}{8} 50.0 \%$ \\
\hline \multirow{2}{*}{ 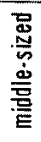 } & massive & $0 \bullet \bullet^{\dagger}$ & $0 \bullet \bullet^{\prime}$ & $\bullet$ & & $\frac{2}{0} 25.0 \%$ \\
\hline & scattered & $\bullet$ & - & $\bullet$ & & $\frac{0}{4} \quad 0 \%$ \\
\hline \multicolumn{2}{|c|}{ Sensitivity } & $\frac{19}{27} \quad 70.4 \%$ & $\frac{20}{25} \quad 80,0 \%$ & $\frac{1}{4} \quad 25.0 \%$ & $\frac{1}{4} 25.0 \%$ & $\frac{41}{60} 68.3 \%$ \\
\hline & & $\begin{array}{l}0 \text { Defect }(+) \\
-"(-)\end{array}$ & $\left.\begin{array}{c}* \\
z \\
\dagger \\
0 \\
x\end{array}\right)$ & me cases & & \\
\hline
\end{tabular}

ranged from 3 days to about 17 years in 30 patients ( $33 \mathrm{MI}$ ) and were unknown in 25 patients $(27 \mathrm{MI})$. Nineteen of $33 \mathrm{MI}$ were studied within 1 month after the onset of $\mathrm{MI}$ and $15(79 \%)$ of them showed positive scintigrams. Thirteen $(93 \%)$ of $14 \mathrm{MI}$ which were studied more than 1 month after the onset of MI had positive scintigrams, but only $13(48 \%)$ of 27 in which the onset of MI was not known had positive scintigrams. In the 55 patients with MI, the intervals from Tl-201 scintigraphy to death ranged from 3 days to 6 years (averagc of 19 months). Nineteen patients with negative scintigrams were dispersed irrespectively of these intervals. In 46 patients without a MI at autopsy, the intervals from $\mathrm{Tl}-201$ scintigraphy to death ranged from 3 days to 6 years (average of 17 months).

II. TI-201 scintigram-Autopsy correlations

The results of a comparative study between pathologic and Tl-201 scintigraphic findings for 60 infarctions are shown in Table I. The Tl-201 scintigram correctly diagnosed the presence of MI in $19(70 \%)$ of 27 cases with an anterior infarction at autopsy, in $20(80 \%)$ of 25 with a posterior infarction, in $1(25 \%)$ of 4 with a lateral infarction and in $1(25 \%)$ of 4 with a subendocardial infarction. In addition, $35(88 \%)$ of 40 cases with a massive large infarction, $4(50 \%)$ of 8 with a scattered large infarction and 2 $(17 \%)$ of 12 with a middle-sized infarction had $\mathrm{Tl}-201$ scintigraphic defects. Fig. 2 shows 3 representative infarctions which were correctly diagnosed with Tl-201 scintigraphy; a massive anterior MI (Fig. 2A), a massive posterior MI (Fig. 2B) and a middle-sized antero-septal MI (Fig. 2C). These three infarctions were transmural and showed thinning of the walls. Nine $(75 \%)$ of 12 MIs with cardiac aneurysms had Tl-201 scintigraphic defects. As 

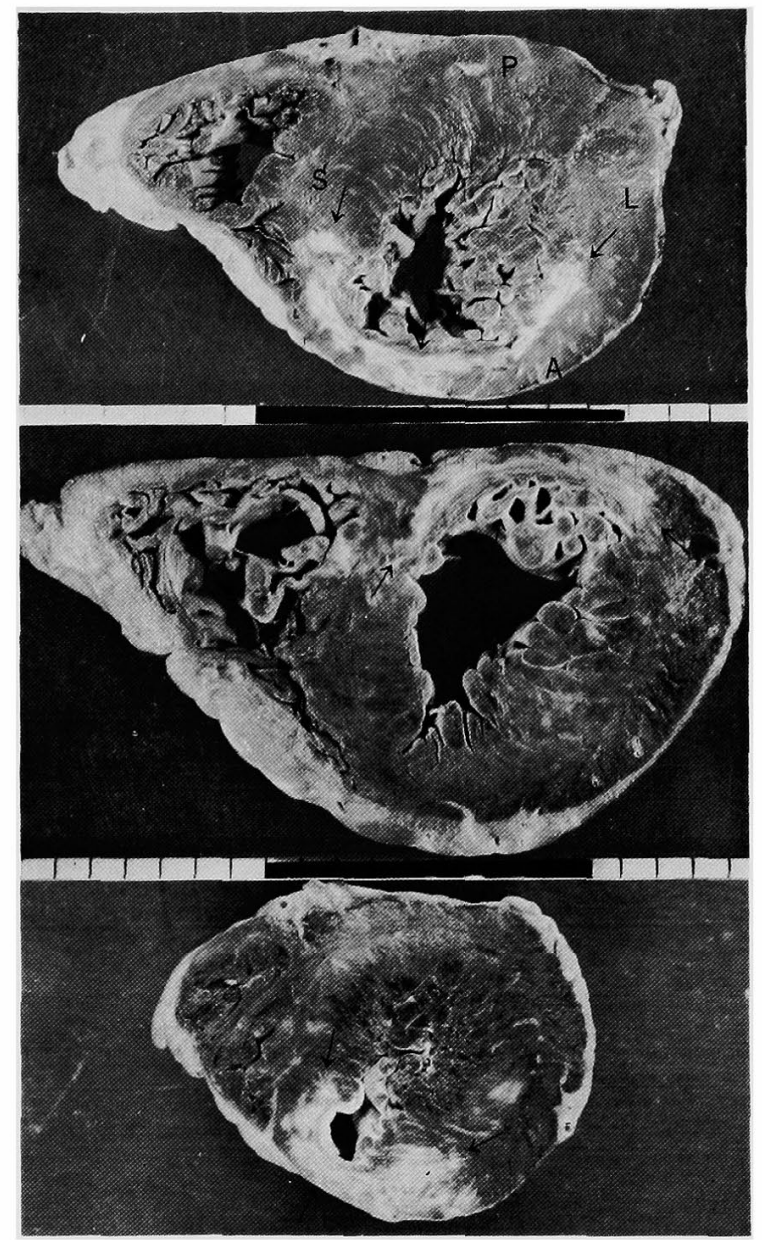

Fig. 2. Transverse sections of the heart viewed from the base. (A) Man, aged 84, massive anterior MI (horizontal length $5 \mathrm{~cm}$, thickness $0.5 \mathrm{~cm}$, longitudinal length $6 \mathrm{~cm}$ ). The distance of the section from the apex was $3.0 \mathrm{~cm}$. (B) Man, aged 81 , massive posterior $\mathrm{MI}(9 \times 0.8 \times 7 \mathrm{~cm})$. The distance from the apex was $4.5 \mathrm{~cm}$. (C) Man, aged 83, massive antero-septal MI $(3.2 \times 0.5 \times 4.7 \mathrm{~cm})$. The distance from the apex was $2.8 \mathrm{~cm}$.

a whole, there was a good agreement in $41(68 \%)$ of 60 infarctions between autopsy results and Tl-201 scintigraphic defects.

III. Diagnostic limit of Tl-201 scintigram in size of MI

The relationship between the size of the MI at autopsy and Tl-201 scintigraphic defects is shown in Fig. 3. Eight infarctions less than $4 \mathrm{~cm}$ in long diameter were not detected by the Tl-201 scintigram; 7 were nontransmural and/or scattered infarctions. Thus, the limit of detection of MIs by the Tl-201 scintigram was $4.5 \mathrm{~cm}$ (long diameter). Fig. 4 illustrates a 


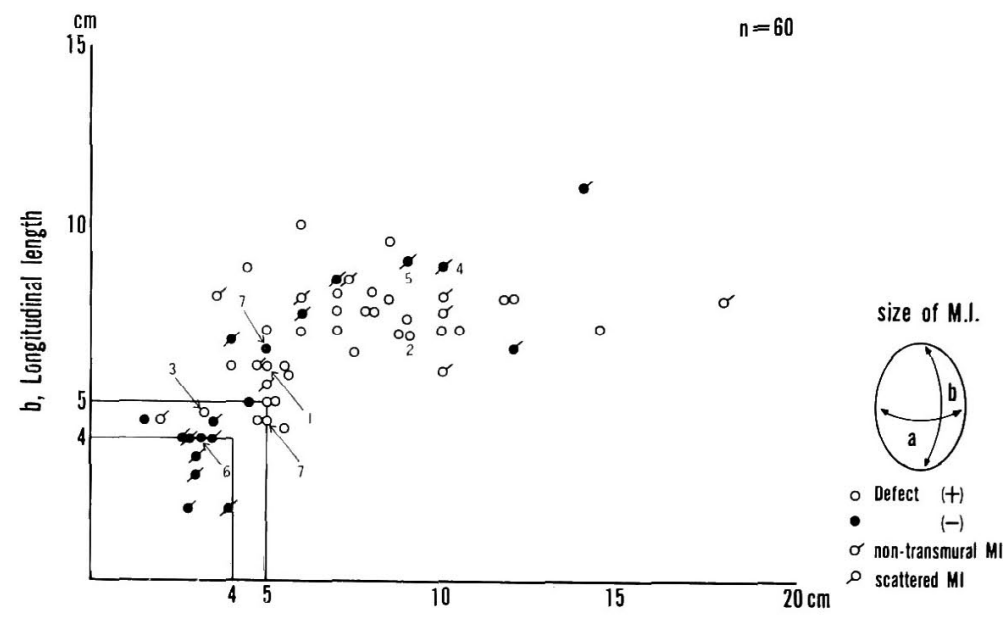

a, Horizontal length

Fig. 3. Diagnostic sensitivity of Tl-201 scintigram on the basis of size of myocardial infarction. The correlation between Tl-201 scintigram and size of MI is illustrated, with horizontal length represented by " a" and longitudinal length of the MI by " $b$ ". Open circle: cases with a positive Tl-201 scintigram, closed circle: cases with a negative scintigram, upper oblique bar from the circle: non-transmural MI, and lower oblique bar: scattered MI. Seven cases numbered from 1 to 7 were shown pathologically; 1: Fig. 2A, 2: Fig. 2B, 3: Fig. 2C, 4: Fig. 5A, 5: Fig. 5B, 6: Fig. 5C, 7: Fig. $7 \mathrm{~A}$ and $7 \mathrm{~B}$.

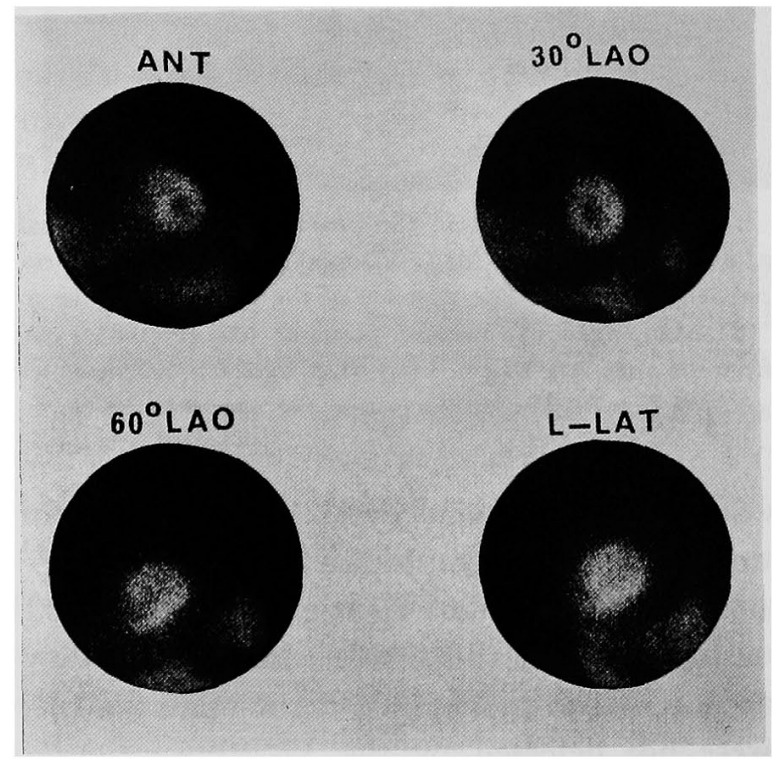

Fig. 4. Tl-201 images at rest in Case 3 (Fig. 2C). Note the perfusion defect in the anterior region. Abbreviation: $\mathrm{ANT}=$ anterior; LAO=left anterior oblique; L-LAT: left lateral. 

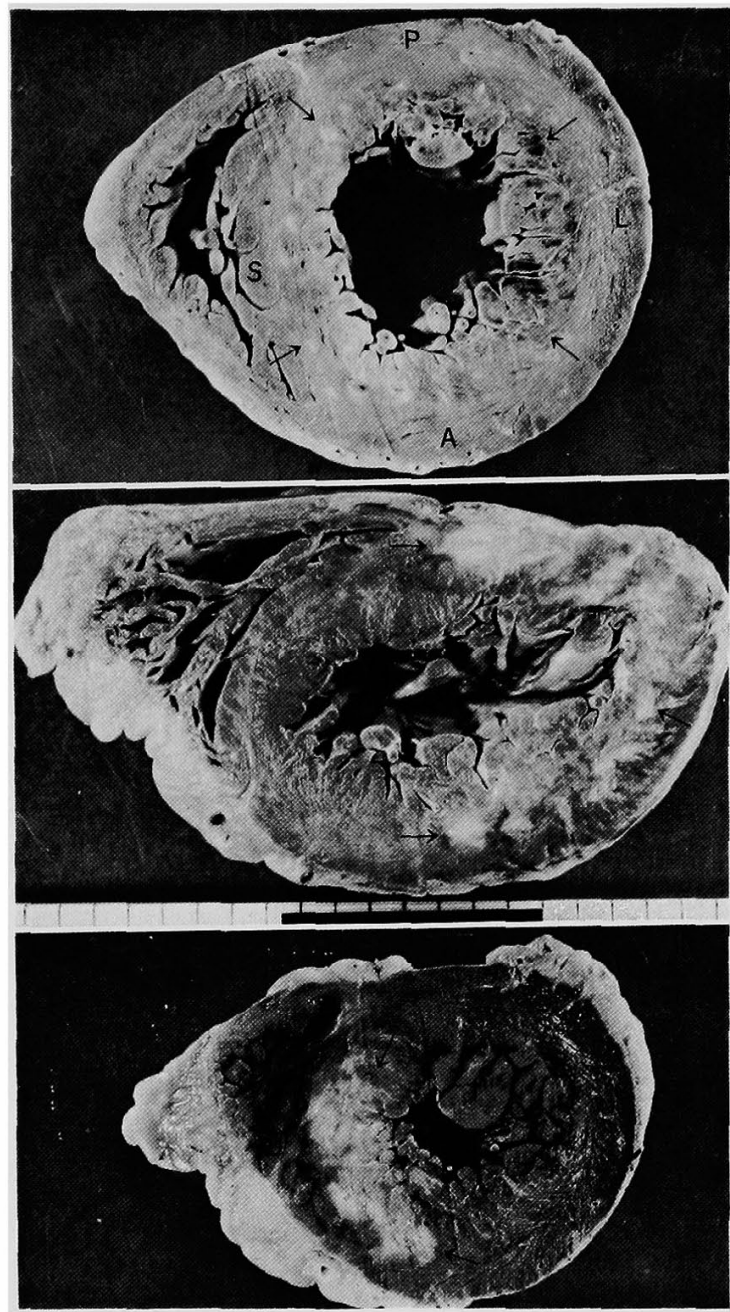

Fig. 5. Transverse sections of the heart. These defects were not detected by $\mathrm{Tl}-201$ scintigrams. (A) Man, aged 84 , circumferential and subendocardial MI $(10 \times 0.8 \times 8.0 \mathrm{~cm})$. The distance from the apex was $5.5 \mathrm{~cm}$. (B) Woman, aged 75, scattered non-transmural lateral MI $(9 \times 1 \times 9 \mathrm{~cm})$. The distance from the apex was $4.0 \mathrm{~cm}$. (C) Man, aged 84, massive anteroseptal MI $(3.2 \times 1 \times 4 \mathrm{~cm})$. The distance from the apex was $3.8 \mathrm{~cm}$.

Tl-201 scintigraphic defect (anterior), which proved to be the smallest infarction $(3.2 \times 0.5 \times 4.5 \mathrm{~cm})$ at autopsy (Fig. $2 \mathrm{G}$ ). Of 43 infarctions more than $5 \mathrm{~cm}, 8$ were not diagnosed by Tl-201 scintigraphy (Fig. 3). Seven of these cases were non-transmural infarctions and 5 of 7 were also scattered infarctions. As a whole, $31(89 \%)$ of 35 transmural infarctions could be diagnosed but only $10(40 \%)$ of 25 non-transmural infarctions could be diagnosed $(\mathrm{p}<0.001)$. 


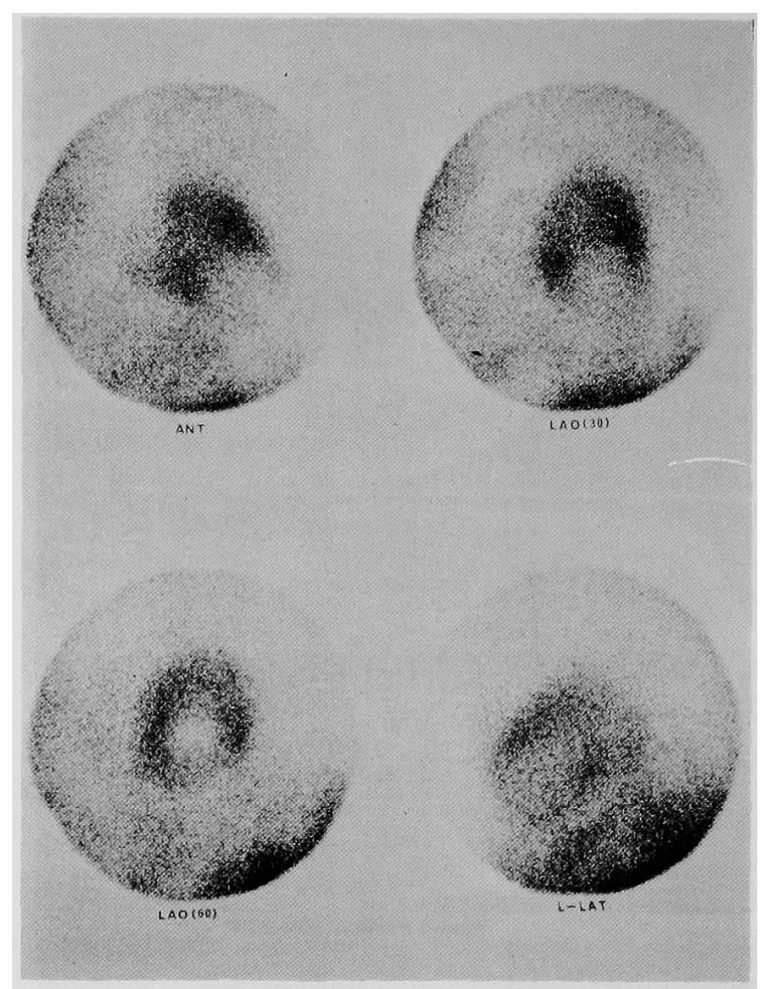

Fig. 6. T1-201 images in Case 7. Note the perfusion defect in the apico-posterior region (partially anterior).

Fig. 5 shows 3 representative infarctions which could not be diagnosed with Tl-201 scintigraphy, a circumferential and subendocardial infarction (Fig. 5A), a scattered large non-transmural lateral infarction (Fig. 5B) and a middle-sized septal infarction (Fig. 5C). The scintigram in Fig. 6 shows an apico-inferior defect but no defect in the high antero-septal area. Pathologic examination showed a large antero-septal infarction with a ventricular ancurysm (Fig. 7A) and an apico-posterior infarction (Fig. 7B). Only one of the 2 infarctions was detected with Tl-201 scintigraphy.

IV. The sensitivity, specificity and diagnostic accuracy

In Table II the sensitivity, specificity and diagnostic accuracy are shown for Tl-201 scintigraphy and ECG on the basis of pathologic findings. The sensitivities of T1-201 scintigraphy and ECG were $68 \%$ and $60 \%$, the specificities were $87 \%$ and $83 \%$ and the diagnostic accuracies were $76 \%$ and $70 \%$, respectively. Three indices were higher for Tl-201 scintigraphy than for the ECG. Six cases with false positive Tl-201 scintigraphy included 2 cases of cardiac amyloidosis, 2 of marked cardiac fibrosis, one of rheumatic endomyocardial fibrosis (Figs. 7G and 8), and one of dilated cardiomyopathy (DCM). Of 

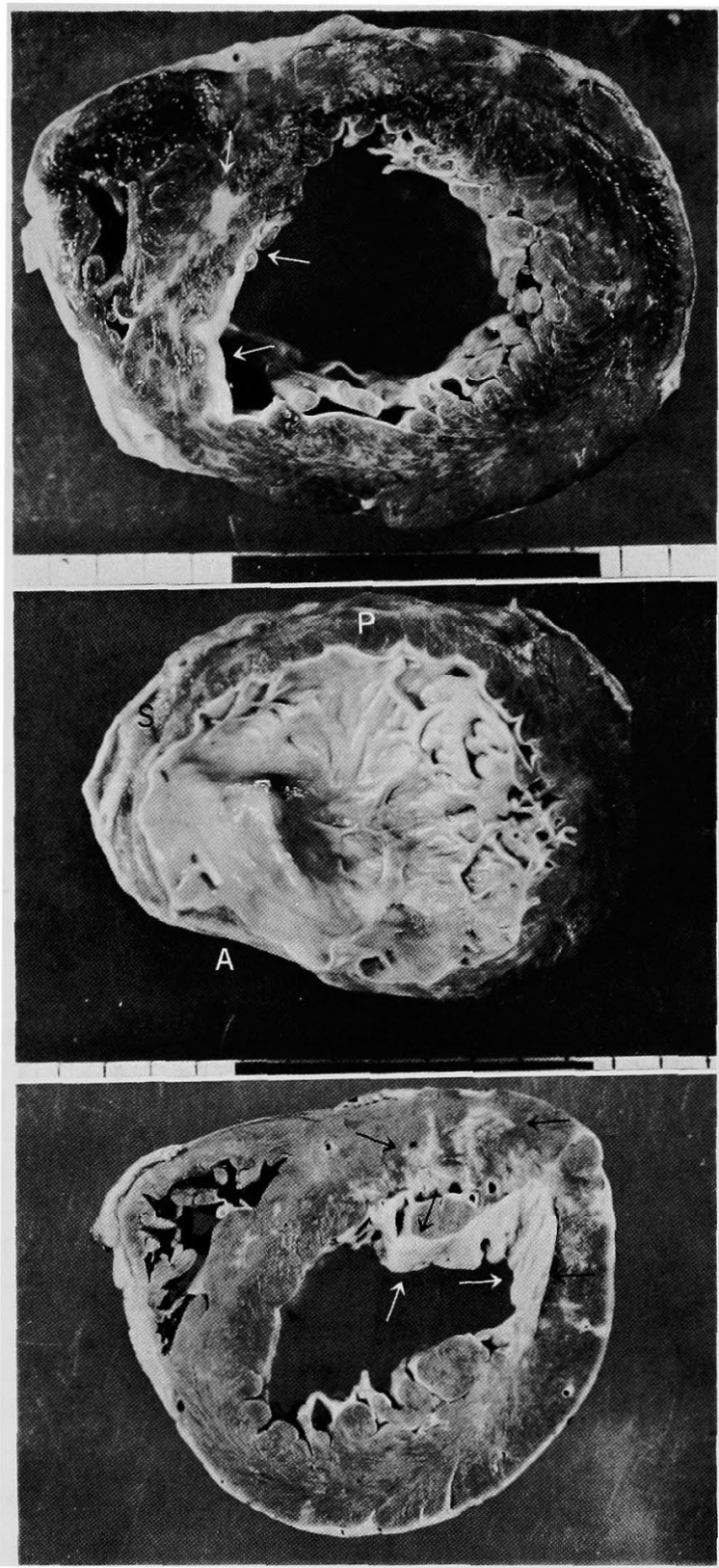

Fig. 7. (A) and (B) represent Case 7 (Fig. 6), woman, aged 87, antero-septal MI $(5 \times 0.2 \times 6.5 \mathrm{~cm})$ with aneurysm formation and an apicoposterior MI $(5 \times 0.5 \times 4.5 \mathrm{~cm})$. The distances were 4.0 and $2.0 \mathrm{~cm}$ from the apex, respectively. (C) Woman, aged 76, fibrosis due to rheumatic endomyocarditis (postero-lateral region). The distance from the apex was $4.1 \mathrm{~cm}$. 


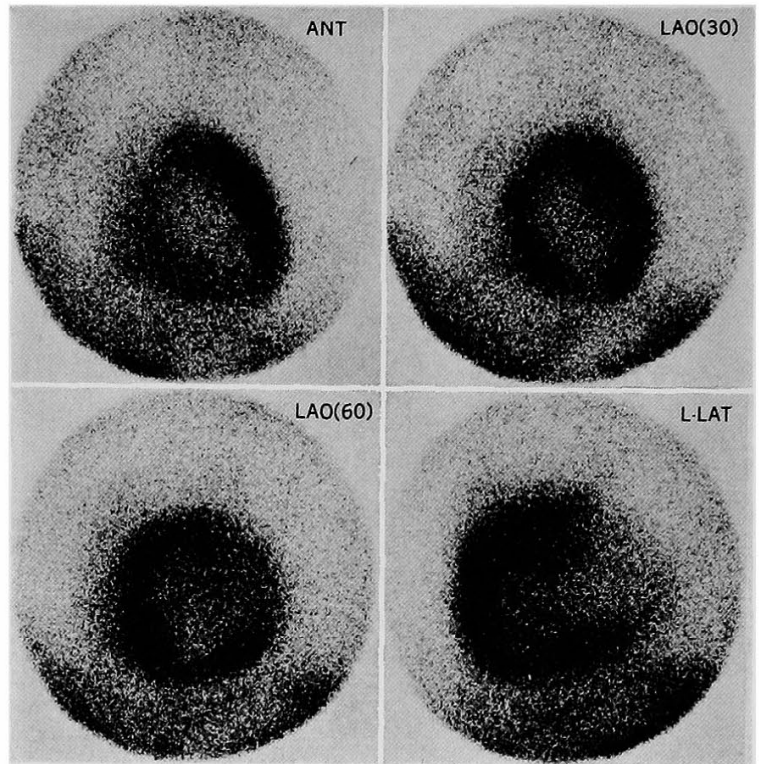

Fig. 8. Tl-201 images in Gase of Fig. 7C. Note the perfusion defect at the posterior region.

Table II. Diagnosis of Myocardial Infarction-Comparisons of the Sensitivity, Specificity and Diagnostic Accuracy between Tl-201 Scintigraphy and ECG-

20 ' $\mathrm{l} \ell$ myocardial scintigraphy

\begin{tabular}{|c|c|c|c|}
\hline $\begin{array}{c}\text { autopsy }^{201} T \ell \\
(t)\end{array}$ & 41 & 19 & 60 \\
\hline $\begin{array}{c}M I \\
(-)\end{array}$ & 6 & 40 & 46 \\
\hline Total & 47 & 59 & 106 \\
\hline
\end{tabular}

Sensitivity $\quad 68.3 \%$

Specificity $\quad 87.0 \%$

Accuracy $\quad 76.4 \%$
ECG

\begin{tabular}{|c|c|c|c|}
\hline autopsy ECG & $(+)$ & $(-)$ & Total \\
\hline $\begin{array}{c}M I \\
(+)\end{array}$ & 36 & 24 & 60 \\
\hline $\begin{array}{c}M I \\
(-)\end{array}$ & 8 & 38 & 46 \\
\hline Total & 44 & 52 & 106 \\
\hline
\end{tabular}

ECG

$60.0 \%$

$82.6 \%$

$69.8 \%$

8 false-positive ECG cases, 2 cases had cardiac amyloidosis, 2 cases scattered scars, 1 case had aortic regurgitation, 1 case had amyotrophic lateral sclerosis and the 2 remaining cases had no significant findings.

V. Comparison of T1-201 scintigram and ECG in diagnosis of MI

Table III compares the Tl-201 scintigram and the EGG in diagnosis of 60 incidents of myocardial infarction. Twenty-seven (45\%) were diagnosed by both Tl-20l scintigraphy and EGG, 14 (23\%) by Tl-201 scintigraphy, $9(15 \%)$ by ECG and $10(16.7 \%)$ by neither method. Thirteen $(48 \%)$ of 
Table III. Comparisons of ${ }^{201} \mathrm{Tl}$ Scintigrams and ECG in Diagnosis of Various Sites of MI

\begin{tabular}{|c|c|c|c|c|c|c|}
\hline \multicolumn{2}{|c|}{${ }_{201} T \ell$ ECG } & Anterior & $\begin{array}{l}\text { Postero- } \\
\text { inferior }\end{array}$ & Lateral & $\begin{array}{l}\text { Subendo- } \\
\text { cardial }\end{array}$ & Iotal \\
\hline 0 & 0 & 13 & 14 & 0 & 0 & $\frac{27}{60} \quad 45.0 \%$ \\
\hline 0 & $x$ & 6 & 6 & 1 & 1 & $\frac{14}{60} 23.3 \%$ \\
\hline$x$ & 0 & 4 & 2 & 1 & 2 & $\frac{9}{60} \quad 15.0 \%$ \\
\hline$x$ & $x$ & 4 & 3 & 2 & 1 & $\frac{10}{60} \quad 16.7 \%$ \\
\hline & $\frac{13}{27} 48.1 \%$ & $\frac{14}{25} 56.0 \%$ & $\frac{0}{4} 0 \%$ & $\frac{0}{4} 0 \%$ & \\
\hline
\end{tabular}

Open circles show the correct diagnosis and crosses represent failure of diagnosis.

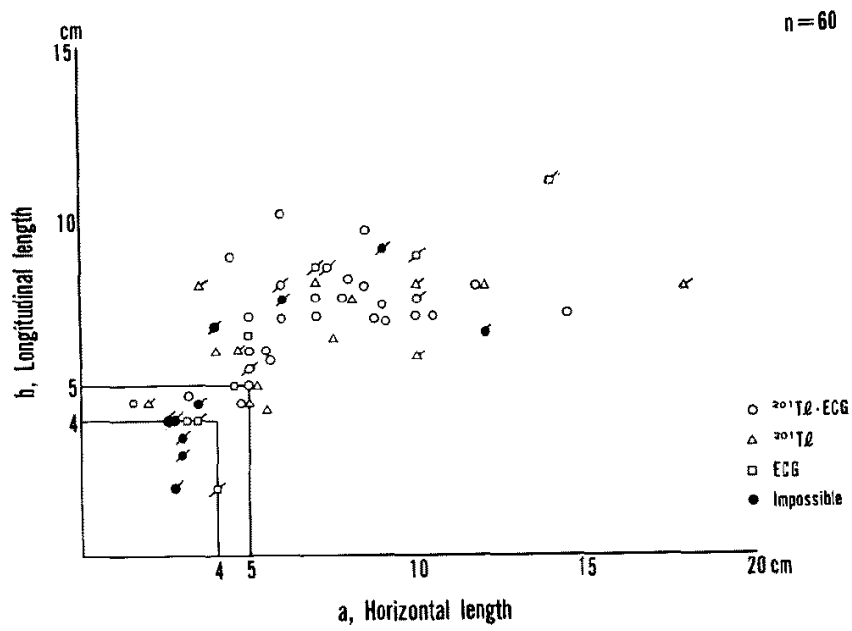

Fig. 9. Comparison of the diagnostic sensitivity of Tl-201 scintigrams and electrocardiogram. The size of MI was presented as in Fig. 3. Open circles represent cases, diagnosed by both Tl-201 scintigraphy and ECG, the triangles only by T1-20l scintigraphy, the squares only by ECG, and closed circles by neither method.

27 anterior infarctions and $14(56 \%)$ of 25 posterior infarctions could be diagnosed by both methods, but none of the 4 lateral and 4 subendocardial infarctions could be diagnosed by either method.

From the view of the size and nature of the MI (Fig. 9), 26 of 27 infarctions diagnosed by both methods were more than $5 \mathrm{~cm}$ (long diameter); only 3 cases were non-transmural and scattered infarctions. Eight of 14 diagnosed only by Tl-201 scintigraphy had massive large infarctions. While 4 of 9 diagnosed only by ECG had a large MI, 3 of these cases were non-transmural 
and/or scattered MI. All 10 which could not be diagnosed by either method were non-transmural and/or scattered MI.

\section{Discussion}

Tl-201 myocardial scintigraphy is a clinically useful method for diagnosis of acute and old MI and angina pectoris. The MI can be visualized as a perfusion defect in Tl-201 scintigraphy, reflecting reduced blood flow and reduced myocardial mass in the infarcted area; partially due to replacement of dead myocardial tissues by scars. ${ }^{10}$ ) However, clinicopathologic correlation studies between Tl-201 scintigraphy and pathologic findings have been infrequent. ${ }^{1-7)}$ Particularly, studies in a variety of MI patients and control subjects have been unsatisfactory in a number of patients. ${ }^{1)-6}$. Wackers et al ${ }^{11}$ examined 9 cases, Bulkley et $\mathrm{a}^{3)} 11$, Nagai et al ${ }^{4)} 12$, Murata et al $^{51} 20$ and Nishimura ${ }^{6} 10$, respectively. In this study, we examined 55 patients with various kinds of MI and 46 control cases without a MI on the basis of pathologic findings.

Wackers et al $^{11}$ reported that the frequency of positive scans was significantly higher (90 of 96) in patients studied within 24 hours of the onset of MI than in patients studied later (75 of 104) and that repeated scintiscans obtained later than 24 hours showed few changes in defect size. Holman ${ }^{10}$ reported that the sensitivity of the technique decreases with time after the onset of symptoms. Fletcher et $a^{12)}$ reported that patients with small infarctions showed a greater reduction in size with time. In our patients with infarctions at autopsy, the latency from the onset of MI to Tl-201 scintigraphy ranged from 3 days to 16 years and the interval from Tl-201 scintigraphy to death was from 3 days to 6 years. Both groups of patients with and without Tl-201 scintigraphic defect were distributed independently of these intervals. Cases with a known MI onset had positive scintigrams more frequently than those in which the onset was not known. However, most cases in which the onset was unknown had middle-sized and/or non-transmural infarctions.

The present study indicates that the ability of Tl-201 scintigraphic to detect defects was higher for posterior infarctions $(80 \%)$ than for anterior infarctions $(70 \%)$. There are reports ${ }^{13), 14)}$ that the detection of defects was lower for postero-inferior infarctions than for anterior infarctions. This discrepancy might be explained by the fact that, in this study, large and scattered infarctions and middle-sized infarctions were more frequent in anterior infarction than postero-inferior infarction. In cases of massive large infarctions, 17 of 18 with anterior infarctions and 17 of 19 with posterior infarctions showed T1-201 scintigraphic defects. The detection of Tl-201 scinti- 
graphic defects in lateral infarctions was low $(25 \%)$, because only 1 of 4 patients had a large and massive infarction.

Several studies ${ }^{11,31,8)}$ have shown that small infarctions are difficult to diagnose with Tl-201 scintigraphy. In this study, 8 cases of MI below $4 \mathrm{~cm}$ (long diameter) could not be diagnosed. Small lesions may be obscured by the surrounding viable myocardium. ${ }^{15}$ Tl-201 scintigrams did not consistently show perfusion defects in 9 cases with infarctions from 4 to $5 \mathrm{~cm}$ (long diameter). Therefore, the T1-201 scintigram could reliably detect MIs greater than $4.5 \mathrm{~cm}$ in long diameter. In experimental studies using phantoms, Ciook et al ${ }^{16)}$ reported that lesions over $2.5 \mathrm{~cm}$ can be seen in any projection and Narita et al $^{17)}$ reported that lesions over $2.5 \mathrm{~cm}$ in diameter were accurately detected with Tl-201 scintigraphy. Mueller et al ${ }^{18)}$ reported that abnormal scintigrams could be detected for smaller deficits in a phantom than in dogs. In reality, though, the diagnostic limit of Tl-201 scintigram in man could be larger $(4.5 \mathrm{~cm})$ than in phantom experiments due to the presence of surrounding tissues of the human body and the beating during the entire cardiac cycle.

Eight cases of large infarction were not diagnosed by Tl-201 scintigraphy; 7 had non-transmural and/or scattered infarction. The remaining falsenegative case had a primarily non-transmural infarction with a partially transmural lesion; only the transmural lesion was detected. In 2 previous studies $^{19},{ }^{20)}$ and this study, the detection of Tl-201 scintigraphic defects was lower for non-transmural infarctions $(40 \%$ to $80 \%$ ) than for transmural infarctions $(88 \%$ to $90 \%)$. This may be due to the presence of viable myocardium in both the infarcted area (as in scattered MI) and surrounding regions. Thus, cases in which perfusion defects in Tl-201 scintigrams were detected had 3 common factors; i) transmural infarction, ii) thinning of the wall in the infarcted area and iii) large (more than $5 \mathrm{~cm}$ for longest diameter) infarction.

The sensitivity of Tl-201 scintigraphy in diagnosis of an old MI, on the basis of pathologic findings, was reported as $72 \%$ by Wackers et al, ${ }^{11} 67 \%$ by Takahashi et al, ${ }^{7} 59 \%$ by Murata et al ${ }^{5)}$ and $100 \%$ by Nagai et al. ${ }^{4}$ By contrast, the sensitivity of ECG on the basis of pathologic findings was reported as $35 \%$ by Alonso et al, ${ }^{21)} 96 \%$ by Savage et $\mathrm{al}^{22}$ and $60 \%$ by Gunnar et al. ${ }^{231}$ Only Takahashi et al ${ }^{71}$ compared the sensitivity, specificity and diagnostic accuracy of Tl-201 scintigraphy with ECG. In acute MI, Wackers et $\mathrm{al}^{11}$ reported that there was a $91 \%$ correspondence between scintigraphic defects and the postmortem location of infarctions and 70\% correspondence between the ECG and postmortem findings. In our study, the sensitivities of Tl-201 scintigraphy and ECG were $68 \%$ and $60 \%$, the specificities were 
$87 \%$ and $83 \%$ and diagnostic accuracies were $76 \%$ and $70 \%$, respectively. Furthermore, T1-201 scintigraphy was more useful than ECG in diagnosis of an old MI. In addition, Tl-201 scintigraphy will be extremely helpful in diagnosis of MI in patients with abnormal conduction disturbances.11),24) In this study, 1 of 2 patients with LBBB and 1 with an intraventricular conduction disturbance showed Tl-201 scintigraphic defects.

False-positive cases were reported in patients with coronary artery disease, ${ }^{25), 26)}$ dilated cardiomyopathy, ${ }^{27)}$ aortic valve stenosis and sarcoidosis. ${ }^{28}$ There were 6 false-positive cases in this study, of which 2 had cardiac amyloidosis, 2 marked cardiac fibrosis, 1 rheumatic endomyocardial fibrosis and 1 dilated cardiomyopathy.

Twenty-seven of 60 cases $(45 \%)$ could be diagnosed by both Tl-201 scintigrams and EGG, 14 (23\%) only by the Tl-201 scintigram, and $9(15 \%)$ only by ECG. A MI could be diagnosed more correctly and more frequently by a combination of methods. In this study, 5 of 9 patients who were diagnosed only by EGG had non-transmural and/or scattered infarctions. Fourteen who were diagnosed only by Tl-201 scintigraphy had MIs of various sizes. Since 8 large infarctions were included in the group, the reason for the failure of ECG diagnosis was not known. Finally, 10 cases could not be diagnosed by either method.

\section{REFERENGES}

1. Wackers FJ Th, Becker AE, Samson G, Sokole EB, vd Shoot JB, Vet AJTM, Lie KI, Durrer $D$, Wellens $H$ : Location and size of acute transmural myocardial infarction estimated from thallium-201 scintiscans. A clinicopathological study. Circulation 56: 72, 1977

2. Bulkley BH, Hutchins GM, Bailey I, Strauss HW, Pitt B: Thallium 201 imagining and gated cardiac blood pool scans in patients with ischemic and idiopathic congestive cardiomyopathy. A clinical and pathologic study. Circulation 55: 753, 1977

3. Bulkley BH, Silverman K, Weisfeldt ML, Burow R, Pond M, Becker LC: Pathologic basis of thallium-201 scintigraphic defects in patients with fatal myocardial injury. Circulation 60: 785,1979

4. Nagai T, Murata K, Torizuka K, Hisada K, Hashimoto S, Sasaki $\mathrm{Y}$, linuma T, Kawai C, Kuramoto K, Suzuki Y, Ishii K: Objective evaluation of Tl-201 image efficacy for detection of myocardial infarction: Report of cooperative research group (II). Shinzo 14: 1115, 1982 (in Japanese)

5. Murata H, Tabuchi H, Toyama H, Muraki T, Tanno M, Chiba K, Yamada H, Ueda K, Sakai M, Fujii J, Okabe A, Aizawa T, Ogasawara K, Kato K: An evaluation of diagnostic efficacy of cardiovascular nuclear medicine for detection of myocardial infarction. Rinsho Hoshasen 28: 551, 1983 (in Japanese)

6. Nishimura T: Clinical Nuclear Cardiology, Nagai Shoten, p 83, 1983 (in Japanese)

7. Takahashi T, Sugiura M, Ohkawa S, Kimura M, Liu J, Sakai M, Matsushita S, Ueda K, Tabuchi $H$, Murata $H$, Chiba K, Yamada $H$ : A correlative study of thallium-201 myocardial scintigrams and pathologic findings in myocardial infarction. Shinzo 16: 895, 1984 (in Japanese) 
8. Sugiura $M$, Okada $R$, Iizuka $K$, lizuka $T$, Hiraoka $K$, Ohkawa $S$, Shimada $H$ : Clinicopathological studies on normality in the aged heart. Jpn J Geriat 6: 297, 1969 (in Japanese)

9. Sugiura $\mathrm{M}$, Okada R: A clinicopathological study on the natural history of myocardial infarction in the aged. Jpn Circ J 36: 1, 1972

10. Holman BL: Myocardial infarct imaging. Am J Cardiol 49: 1347, 1982

11. Wackers FJ Th, Sokole EB, Samson G, vd Shoot JB, Lie KI, Wellens HJJ: Value and limitations of thallium-201 scintigraphy in the acute phase of myocardial infarction. New Engl J Med 295: 1, 1976

12. Fletcher JW, Mueller HS, Rao PS: Sequential thallium-201 myocardial scintigraphy after acute infarction in man. Nucl Med 136: 191, 1980

13. Niess GS, Logic JR, Russell RO, Rackley CE, Rogers WJ: Usefulness and limitations of thallium-201 myocardial scintigraphy in delineating location and size of prior myocardial infarction. Girculation 59: 1010, 1979

14. Blood DK, McCarthy DM, Sciacca RR, Cannon PJ: Camparison of single-dose and doubledose thallium-201 myocardial perfusion scintigraphy for the detection of coronary artery disease and prior myocardial infarction. Circulation 58: 777, 1978

15. Murata H, Iio M, Toyama H, Kawaguchi S, Chiba K, Yamada H, Matsui K, Ueda K, Ohkawa S: Diagnosis of myocardial infarction using ECG gated RI cardiography. Shinzo 9: 107, 1977 (in Japanese)

16. Cook DJ, Bailey I, Strauss HW, Rouleau J, Wagner HN, Pitt B: Thallium-201 for myocardial imaging: Appearance of the normal heart. J Nucl Med 17: 583, 1976

17. Narita M, Usami M, Kurihara T, Kawaradani H, Honda M, Ogawa T, Kanao K: Noninvasive detection of regional myocardial perfusion abnormality by scintigraphic technique. Jpn J Nucl Med 15: 57, 1978 (in Japanese)

18. Mueller TM, Marcus ML, Ehrhardt JC, Chaudhuri T, Abboud FM: Limitations of thallium201 myocardial perfusion scintigrams. Circulation 54: 640, 1976

19. Strauss HW: Cardiovascular nuclear medicine. A new look at an old problem. Radiology $121: 257,1976$

20. Wackers FJ Th: Thallium-201 myocardial scintigraphy in acute myocardial infarction and ischemia. Seminars Nucl Med 10: 127, 1980

21. Alonso DR, Scheidt S, Post M, Killip T: Pathophysiology of cardiogenic shock. Quantification of myocardial necrosis, clinical, pathologic and electrocardiographic correlations. Girculation 48: 588,1973

22. Savage RM, Wagner GS, Ideker RE, Podolsky SA, Hackel DB: Correlation of postmortem anatomic findings with electrocardiographic changes in patients with myocardial infarction. Retrospective study of patients with typical anterior and posterior infarcts. Circulation 55: 279,1979

23. Gunnar RM, Pietras RJ, Blackaller J, Dadmun SE, Szanto PB, Tobin JR Jr: Correlation of vectorcardiographic criteria for myocardial infarction with autopsy findings. Circulation 35: 158,1967

24. Hirzel HO, Senn M, Nuesch K, Buettner C, Pfeiffer A, Hess OM, Krayenbuehl HP: Thallium-201 scintigraphy in complete left bundle branch block. Am J Cardiol 53: 764, 1984

25. Gewirtz H, Beller GA, Strauss HW, Dinsmore RE, Zir LM, McKusick KA, Pohost GM: Transient defects of resting thallium scans in patients with coronary artery disease. Circulation 59: 707, 1979

26. Wackers FJ Th, Lie KI, Lien KK, Sokole EB, Samson G, vd Shoot JB, Durrer D: Thallium201 scintigraphy in unstable angina pectoris. Circulation 57: 738, 1978

27. Bailey IK, Come PG, Kelley DT, Burlow RD, Griffith LSC, Strauss HW, Pitt B: Thallium201 myocardial perfusion imaging in aortic valve stenosis. Am J Cardiol 40: 889, 1977

28. Bulkley BH, Rouleau JR, Whitaker JQ, Strauss HW, Pitt B: The use of 201-thallium for myocardial perfusion imaging in sarcoid heart disease. Chest 72: 27, 1977 